\title{
NAÇÃO E IDENTIDADE NACIONAL NO LIVRO DIDÁTICO DE HISTÓRIA: A ABORDAGEM DE BORGES DOS REIS NA BAHIA REPUBLICANA1
}

\author{
Maria Cristina Dantas Pina \\ mcristina.pina@gmail.com \\ Universidade Estadual do Sudoeste da Bahia \\ (UESB/Museu Pedagógico)
}

\section{RESUMO:}

O texto analisa como a nação brasileira foi retratada no manual de História do Brasil de Antônio Alexandre Borges dos Reis (1915), utilizado no Ginásio da Bahia. Buscou-se perceber as especificidades do discurso histórico do autor, testemunha das contradições de uma região que clamava por manter sua posição no cenário nacional. Através da revisão bibliográfica e de fontes primárias o objeto foi analisado segundo três categorias: nação, trabalho e classe social. Constatou-se que, semelhante a outros autores didáticos da época, Borges dos Reis defende um caminhar evolutivo do Brasil em direção à civilização, fortalecendo uma identidade nacional branca, cristã e liberal. Condena moralmente a escravidão, mas a justifica como necessidade econômica; admite o papel do negro na construção do país, porém sem ação decisiva no destino do Brasil. Todavia, diferente daqueles manuais, o autor chama atenção para o processo de interiorização e de mistura entre as raças na formação da nação, defendendo que as diversidades regionais deveriam ser consideradas na narrativa. A obra caracteriza-se pelo patriotismo e nacionalismo, embora referenciado no contexto baiano, evidenciando o quanto as noções de patriotismo, nacionalismo e identidade nacional assumiram complexidades específicas no Brasil republicano, tendo na escola e seus materiais didáticos lugares privilegiados de disseminação.

Palavras-chave: Livro Didático, Nação, Bahia, Identidade Nacional, Borges dos Reis

\section{ABSTRACT:}

This text seeks to analyze the way in which the Brazilian Nation was portrayed in the text book "History of Brazil", written by Antônio Alexandre Borges dos Reis (1915), and used by the 'Ginásio da Bahia' (The High School of Bahia). We reveal the specific tenets of the author's historical argument, pointing out the contradictory status of a region such as Bahia which at that time was clamouring to maintain its role within the Nation as a whole. Through bibliographical revision, as well as through primary fonts of information, our intention has been to proceed through the analysis of three specific categories: Nationhood, Work, and Social Class. Similar to other authors of the period, Borges dos Reis advocated an evolutionary course of Brazilian development, with regards to civilization, thereby strengthening a National identity based on being white, Christian and Liberal. He condemns slavery on moral grounds, but justifies it as an economic necessity; he admits that the negros played their role in the building of Brazil, however irrelevant their actions may have been to the destiny of the country. On a unique note, and contrary to the textbook writers of the time, Borges dos Reis pinpointed the process of colonizing the hinterlands and the mixing of races as being important factors in the forging of the Nation, while defending the view that regional diversity should also be considered in the narrative. His work is marked by patriotism and nationalism, although his references were clearly set in the context of Bahia, which serves as evidence to show how much the notions of 
patriotism, nationalism and social identity assumed specific, complex, characteristics during the Republican period, using the priveleged position of the school, and its didactic materials, for the dissemination of such notions.

Keywords: Didactic book, Nation, Bahia, National Identity, Borges dos Reis

\section{Introdução}

O livro didático é um instrumento importantíssimo para consolidação e disseminação de uma determinada memória histórica que, por sua vez, marca fortemente a representação de gerações inteiras que passam pela escola. Assim, pela sua trajetória, é possível identificar as abordagens privilegiadas e silenciadas na memória e os seus desdobramentos na construção e consolidação de uma visão de mundo.

Os estudos sobre o livro didático têm dialogado com áreas diferenciadas da história da educação. Uma primeira delas é a história do ensino que recorre ao livro como fonte privilegiada para compreensão dos percursos dos métodos e conteúdos de ensino. No campo do ensino de história destacam-se os trabalhos de Fonseca (2001) e Mello (1997). Outra perspectiva é o da história das disciplinas escolares e do currículo, na qual o livro didático é revelador tanto das mudanças sofridas pelas disciplinas escolares quanto dos enfoques e silêncios construídos nesse processo, sendo exemplares as análises de Bittencourt (1993; 2007) e Fonseca (2004), que adentraram na história do ensino de história para problematizar os significados do currículo escolar de história.

Destaca-se, ainda, a história das instituições escolares, que tem buscado esse material didático como fonte importante para entender os valores e as concepções forjados e divulgados pelas instituições escolares ao longo do tempo [Mattos (2000; 2007), Gasparello (2004), Mello (1997)].

Aqui se trabalha com a perspectiva da história da educação, particularmente da disciplina história. Entende-se que o livro didático de História do Brasil funcionava entre o final do século XIX e primeiras décadas do século XX como instrumento para organizar, consolidar e justificar uma formação social específica, que é a nação brasileira. Nesse projeto de nação, as especificidades regionais foram destacadas e valorizadas como forma de explicar a situação em que se achavam as regiões ou estados brasileiros. Os interesses das classes sociais dominantes em seus locais eram preservados e justificados em nome da história. Os livros didáticos eram, assim, instrumentos importantes de divulgação de um projeto de classe via narrativa da história do Brasil.

Dessa forma, entende-se o livro didático de história, também, como um importante instrumento forjador de uma identidade nacional que, em contextos diversos, atendeu a visões de mundo dominantes. No adentrar do século XX ele serviu de forjador de uma concepção de cidadania republicana, em que a formação étnica do Brasil foi elemento explicativo e diferenciador nas representações construídas pelos autores didáticos.

Neste texto analisa-se um manual didático específico, O livro de História do Brasil, de Antônio Alexandre Borges dos Reis, publicado pela primeira vez em 1906, abarcando a trajetória do Brasil do descobrimento ao século XVIII. Em 1915 o autor publica uma segunda edição, acrescida de uma segunda parte sobre a história do século XIX até a Proclamação da República. Foi escrito para ser utilizado nas aulas de História do Brasil no Ginásio da Bahia, ministradas pelo próprio autor, portanto para ser divulgado e apropriado pelo público escolar baiano. O interesse é identificar até que ponto este autor reproduziu, ou inovou os manuais de circulação nacional. Seu manual foi publicado por sua própria editora, com uma circulação concentrada regionalmente. Borges dos Reis era um 
intelectual do Instituto Geográfico e Histórico da Bahia (IGHB), onde manifestou em alguns momentos uma defesa das qualidades do negro e de sua participação na formação do Brasil, além do estudo minucioso da etnografia indígena baiana. Ou seja, até que ponto Borges dos Reis construiu um caminho diferenciado. Como pensou o Brasil e suas diferenças regionais? Como sua realidade influenciou na sua reconstrução do passado nacional?

$\mathrm{O}$ artigo divide-se em três momentos: uma explanação do contexto baiano vivido pelo autor e pelos leitores do livro; uma discussão do autor e obra, identificando recortes biográficos e analisando o conteúdo da obra no que diz respeito a construção das idéias de nação e identidade nacional e, por último, algumas conclusões no sentido de apontar as especificidades da visão do autor naquele momento.

\section{A Bahia Republicana}

A partir das últimas décadas do século XIX viveu-se um período de instalação e construção dos instrumentos político-institucionais da República, e a escola era um desses alvos privilegiados de atuação. Aquele foi um momento intenso de disputas de ideais, projetos, interesses de toda ordem, em que os diversos grupos sociais procuravam manter privilégios e dar direção às mudanças.

Na Bahia, a transição do Império para a República não diferiu no geral do contexto nacional. Dominada política e economicamente por oligarquias rurais, esse estado experimentou essa passagem baseada em acordos entre as elites agrárias.

As transformações ocorridas no contexto mundial, na transição do século XIX para o século XX atingiram o Estado da Bahia intensamente. As novas demandas do capitalismo internacional provocaram mudanças numa economia dependente da escravidão e da exportação do açúcar.

A Bahia constituía-se, no período colonial e parte do imperial, num dos principais centros político e econômico do Brasil, sustentada na agroexportação escravista. Adentrando o século XVIII, além de exportadora de açúcar e produtos do sertão, a Bahia passa a ser o centro de escoamento do ouro de Minas Gerais. Entretanto, até meados do XIX, a pujança da economia baiana sustenta-se na produção açucareira e fumageira, fortemente escravista e voltada para exportação. Daí em diante, a Bahia começa a sofrer sérios abalos.

Também especializou-se como um centro financista, fortemente enriquecido com o tráfico negreiro e a intermediação do comércio agroexportador. Além disso, era um poderoso centro comercial, com um dos principais portos do país; constituía-se como a principal porta de entrada dos produtos europeus e africanos, dali direcionados para outros locais do país. A partir de 1860, a economia baiana sofre intensa crise, profundamente enraizada com as transformações na conjuntura internacional, fruto do desenvolvimento do capitalismo e que vai se acentuar com o estabelecimento da República. Os grupos ligados à economia mercantil/financeira sofrem o abalo com o redirecionamento do centro hegemônico do desenvolvimento produtivo do país para o Rio de Janeiro e São Paulo, com a crescente produção e comercialização do café, novo produto priorizado na pauta de exportação.

Esse contexto político-econômico da Bahia republicana trouxe repercussões no campo educacional. A Bahia viveu suas experiências de reformas educacionais no bojo do 
época: as revistas Nova Cruzada e Grêmio Literário. Alem disso, a partir de 1888, montou uma tipografia e passou a exercer a função de editor. Foi proprietário da Casa Editora Reis \& Cia. e organizou e editou o Almanaque do Estado da Bahia (1898 a 1920 - 10 volumes), além de seus próprios livros, entre eles, os didáticos.

Além das funções intelectuais, Borges dos Reis participou também da vida política local. Foi deputado estadual no governo de Severino Vieira (1905/1906 - 1907/1908) e diretor da Associação Comercial da Bahia (1899 - 1900)2.

Dessa forma, entender suas formulações sobre o Brasil significa visualizar um debate mais amplo no meio intelectual baiano que buscava explicações para a situação da Bahia frente o Brasil naquele momento.

O livro didático de História do Brasil, produzido no contexto aqui em foco, tinha, em geral, como característica central uma narrativa centrada na formação da nação e do Estado. Os autores construíam suas obras de maneira a destacar a constituição e desenvolvimento da nação brasileira. Nesse processo, buscavam valores do seu presente que consideravam essenciais na ordenação da narrativa na busca do que pretendiam destacar.

Os livros de João Ribeiro e Rocha Pombo, por exemplo, analisados em trabalho anterior3, seguem este caminho e, tirando as diferenças das narrativas, reforçam um caminhar da história nacional rumo à República, caracterizada como forma mais civilizada de sociedade, marcada pela unidade das três raças em nome de um projeto de nação e pátria única e una.

A Bahia republicana viveu o processo do pós-abolição inserida numa crise econômica de perda de hegemonia para o sudeste, porém mantendo hierarquias sociais sustentadas em prestígio político, fortemente marcado pela cor/raça. A sociedade baiana, particularmente Salvador, enfrentou a contradição da presença maciça da população negra recém-saída da escravidão e os percalços na organização de um modelo de sociedade urbana, branca e européia.

Essa questão estava presente na instituição escolar, principalmente no Ginásio da Bahia, que representou um importante centro de formação da elite baiana, que aglutinava intelectuais ligados às classes dominantes responsáveis pela formação de opinião e participantes ativos em outros espaços de circulação de idéias como os jornais e o IGHB.

Nesse sentido, é preciso analisar o discurso histórico de Borges dos Reis tendo referência as lições de Bloch (1997) quando afirma que a história é "a ciência dos homens no tempo", ou ainda como Fontana (2004) para quem a história é construída para legitimar projetos de classe. Assim, percebe-se no texto deste autor as apreensões e projetos que orientaram seu olhar sobre o passado. O que Borges dos Reis buscava legitimar? O que pretendia consolidar como memória nacional e quais os seus motivos?

A obra de Borges dos Reis caracteriza-se por apresentar uma análise dos fatos históricos sem se sustentar na narrativa pura e simples de fatos da história políticoadministrativa do Brasil. Preocupa-se, a todo o momento, em apoiar sua análise em estudiosos da história nacional e mundial, tentando explicar os fatos e não apenas descrevê-los. Organiza a narrativa a partir dos marcos políticos e econômicos, incorporando, em alguns capítulos, o movimento de ocupação do interior, como fez João Ribeiro.

O livro é dividido em duas partes. A primeira, editada em 1906, cobre os fatos do período que vai do século XVI ao XVIII (colonização, formação étnica brasileira, jesuítas, inconfidência, escravidão) e é composta de 257 páginas; a segunda, editada em 1915, junto a uma segunda edição da primeira, cobre os fatos ocorridos no século XIX (independência, império, abolição, república) e é composta de 168 páginas. 
Numa edição do Diário da Bahia, de 30 de janeiro de 1906, quando do lançamento da primeira parte do manual de Borges dos Reis, foi ressaltado o caráter inovador do livro e seu distanciamento da tradicional narrativa linear, sem análises profundas. O jornal chamava atenção justamente pela profundidade de análise da obra e sua visão ampla do Brasil.

O que porém de muito valor torna o livro é a forma que lhe deu o seu auctor, moldando-o para a educação da juventude e ampliando com a narração dos factos o horizonte do leitor pela evocação do estudo das terras, dos climas, das águas, da configuração do solo e das diversas versões sobre a descoberta.

[...] Muitas das coisas banaes, das trivialidades copiadas dos anteriores, foram evitadas, ou, o que é melhor, contadas com o acompanhamento dos resultados dos estudos ulteriores e da crítica. (Diário da Bahia, 30.01.1906, IN: REIS, 1915, p. II e III)

O próprio Borges dos Reis persegue, desde seu prefácio, em 1905, esse ideal de uma história que dê conta da amplitude e diversidade que é o Brasil. Como prefácio cita um longo trecho de Sílvio Romero e pergunta ao leitor se terá ele conseguido tal objetivo. Vale a pena citar o referido texto, pois muito nos diz do projeto de história deste autor.

$\mathrm{O}$ verdadeiro historiador do Brasil deveria ser bastante naturalista para no pórtico de seu livro distender a descripção vasta, exacta, verdadeira da terra nacional, determinando-lhes as zonas, os climas os aspectos; todos os cem modos diversos pelos quais os meios collaboram com os homens; deveria ser bastante ethnologista para comprehender e amar as diversas raças, que levantaram neste paiz as suas tendas e agitaram à luz do sol brasileiro seus músculos de combatentes, travando a lucta da vida, a lucta da civilização; para estendel-as em seus cantos, em suas aspirações; deveria ser bastante philantropo e democrata para rir e chorar com o povo, seguil-o na sua formação gradativa e suas transformações progressivas, assistir a geração do nosso terceiro estado e da nossa burguesia, acompanhal-os na vida municipal, nas agitações da vida política, nos anhelos de liberdade; deveria ser bastante economista para sorprehender o povo no seu trabalho, tomar nas mãos os fios determinadores da formação de nossa riqueza publica e particular, mostrando a irradiação desse pólipo enormissimo - a escravidão -, pólipo de nova espécie, fecundo, productor, sugado pelo parasitismo immenso e informante, o grande crime da raça colonizadora, o grande crime que tem feito, que ainda hoje faz a nossa historia ser uma obra de privilegio e iniqüidade; deveria ser bastante phylosopho - para ter uma nítida idéia da cultura e dos destinos humanos, comprehender a formação das patrias recentes, o advento dessas nações coloniaes mestiçadas, herdeiras de antigas glorias e antigos ideaes, prestes a transformar-se, urgidas por necessidades novas; deveria ser bastante erudito para conhecer a fundo todos os factores, todas as peripécias do passado nacional; deveria finalmente ser bastante poeta para construir de tudo isso uma obra artística, viva, palpitante de seiva e de enthusiasmo. (ROMERO, S. In: REIS, 1915, p. v-vi).

Este foi o caminho que Borges dos Reis tentou perseguir em sua narrativa. Logo de início, quando discute as navegações e o descobrimento, apresenta o debate historiográfico ocorrido no IGHB sobre a intencionalidade ou casualidade do descobrimento. Defende a tese do descobrimento apesar de concordar com os conhecimentos prévios de Cabral e a primazia de Portugal nos mares. 
A narrativa de Borges dos Reis é envolvida de referências a outros estudos sobre o Brasil. Quando trata da tomada do território e as guerras com os indígenas, recorre várias vezes a Capistrano de Abreu. Dessa forma é fundamental entender que o sertão ocupa um lugar privilegiado na análise, evidenciado através dos movimentos de conquista e ocupação do território.

Era um intelectual baiano falando a partir dos ressentimentos de uma região outrora pujante e central no desenvolvimento da nação que naquele momento encontrava-se em plena crise econômica.

Após a descrição da empreitada portuguesa pelos mares, Borges dos Reis passa à descrição do nosso território e seus habitantes. Demonstra conhecimentos etnográficos sobre os indígenas, por ele considerados selvagens, apresentando várias citações de estudiosos sobre paleontologia brasileira4.

Analisa a colonização a partir da idéia que no Brasil houve feudalismo, simbolizado pelas capitanias hereditárias, as quais, na sua opinião, não tiveram sucesso. Contrário a outros autores da sua época, Borges dos Reis defende a tese do fracasso das capitanias.

Não assim as capitanias brazileiras, inçadas de habitantes bellicosos, enormes em extensão, afastadas da metropole por centenares de léguas.

Estas circunstancias eram bastante a justificar o insuccesso do regimen, se outras não se lhes viessem juntar - como a pobreza relativa dos donatarios, a falta de cohesão na ordem administrativa e a completa incapacidade de quase todos os seus proprietarios ou capitães (REIS, 1915, p.47).

Para ele a sociedade colonial era organizada em três classes: fidalgos, peões e gentios/escravos. Apresenta a relação entre as classes a partir da idéia de miscigenação, já que a sociedade era composta por três raças: branco, índio e negro (p. 53).

Essas classes, podendo ser assim delimitadas, não se isolavam, não faziam vida á parte como no feudalismo europeu: misturavam-se, almagamavam-se, confundiam-se, pelo choque, pela exploração, pela nota da cupidez e sensualismo, que era a moral dominante de tão encontrados e hecterogeneos elementos e proliferarem na pujança da natureza tropical. Em breve trecho, pois, a mestiçagem avolumou-se: surge o mameluco, producto do cruzamento do portuguez com a raça indigena, sempre activo e irrequieto, mas nem sempre benévolo e humano: - (se na fundação do arraial de S. Paulo vemol-o enfrentar até os jesuitas, o encontramos mais tarde como o mais ferrenho perseguidor da raça materna, no typo odioso de caçador de indígenas;) - junta-se-lhe o curiboca, crusamento de negro com a indigena, e o mulato, resultado identico da negra com o branco (REIS, 1915, p.53).

Ao apontar as características de cada uma dessas raças primárias, ressalta a superioridade do branco e seu papel central na formação do Brasil. O modelo de Von Martius fica explícito no desenvolvimento da narrativa. Porém, aponta na análise a presença ou possibilidade de uma raça originária brasileira, nascida de todos os cruzamentos.

Ethnicamente, pois, era essa a sociedade; politica e juridicamente, a feição da colonia na primeira phase de sua historia pode ser synthetisada nas seguintes palavras; o pórtuguez explorando o sólo pelo trabalho negro e exterminando o indigena, já por não se prestar este ao regimen, já por vir pertubal-o n'aquella tarefa; situação assente em princípios os mais absolutos e intorelantes e sempre intranquilla, ora pelas luctas intestinas que a propria cobiça accendia, ora pela repulsa e aggressão do íncola, ora, finalmente, pelos ataques e assaltos de inimigos externos - francezes, 
hespanhoes, hollandezes, inglezes, a disputarem a preza rica que a setença papal houvera doado e confirmado ás lusas quinas (REIS, 1915, p.53).

E, prepara, pela absorpção, pela modelação final, a raça forte que ha de firmar a hegemonia da nossa patria na América latina (REIS, 1915, p.54).

Há aqui uma defesa da miscigenação como caminho positivo para o Brasil. Pensamento que ia de encontro a toda uma formulação dominante que condenava e ressaltava os malefícios dos cruzamentos com raças inferiores. Para ele, pelo contrário, a mestiçagem possibilitava o aproveitamento das melhores características de cada raça, inclusive as inferiores Também é possível perceber neste trecho a idéia de uma raça tão presente em Euclides da Cunha, na descrição dos Sertões, quando constrói a idéia do brasileiro como forte, fruto do cruzamento das raças e do convívio com as adversidades do território.

Ainda analisando a colonização, apresenta os jesuítas como essenciais nesse processo. Nesta parte, seu texto é muito parecido com outros manuais da época, os jesuítas são, pra ele, os representantes da cultura intelectual da época e da moral necessária.

Outro papel importante coube aos indígenas, principalmente na defesa do território, por seu espírito guerreiro. Porém, justifica sua escravização pela necessidade de utilização da mão-de-obra indígena na agricultura e pelas próprias características dessa raça - fraco, indolente e insubmisso ao trabalho, o índio era antes de tudo um selvagem em comparação ao branco civilizado.

Aqui também está presente a idéia de inferioridade da raça para explicar a escravidão indígena, embora em vários momentos condena os portugueses nesse processo por ter perdurado esta situação até o século XIX. Assim descreve o índio brasileiro:

[...] prestava valiosos serviços ao colonizador, combatendo a tribu adversa, ensinando áquelle os ardis, os caminhos, a estrategia íncola, dominada pelo espirito guerreiro, que lhe constiuia a feiçaõ principal do caracter". "Quando escrava, mostrava-se fraca e indolente ao trabalho, insubmissa ao eito, sempre disposta a ganhar a selva proxima, guarida da liberdade que se lhe arrancava e onde podia continuar a vida da natureza, descuidada e ociosa." (REIS, 1915, p.54).

Ressalta a defesa dos jesuítas em relação aos índios e sua luta contra a escravização, cumprindo um papel essencial ao catequizar o indígena, levando o mesmo a entrar em "contato com o Evangelho, elevando sua condição moral" (p.224).

Graças a elles, poude a raça aborigene, combatida em sua fereza pela catechese christã e mais por este processo, do que pelas armas, em parte, submettida, escapar a completo exterminado.(p.56).

Apropriando-se da linguagem dos íncolas, apresentando-se-lhes simples, modestos, resignados, humildes, estóicos, dando-lhes o exemplo de todas as virtudes Moraes, puderam os jesuitas ganhar o animo dos selvagens, iniciar e desenvolver a obra da civilisação (REIS, 1915, p.56).

Além dos indígenas, Borges dos Reis ressalta a presença negra. Para ele o negro foi "um factor poderoso da nossa nacionalidade, pelo numero, pela feição affectiva de seu caracter, pela sua intensa proliferação.” (p.55). Explica a escravidão pela não adaptabilidade do indígena ao trabalho, o que ugere o contrário em relação ao negro:

A insubmissão do aborígene ao trabalho, a sua inadaptação, como máquina, à vida agrícola, a oposição e a concorrência dos jesuítas obstando até a locação dos serviços dos indígenas aldeiados - foram pois as causas que determinaram a introdução dos africanos escravos no Brasil (REIS, 1915, p. 135). 
A partir dessa justificativa, chama a atenção para a existência da escravidão na Europa antes do descobrimento do Brasil. Demonstra como a descoberta da costa ocidental africana pelos portugueses possibilitou a expansão desse comércio de negros. Assim, afirma que "as expedições marítimas ao estabelecerem feitorias na Costa d'África, naquela época, não tinham outro objetivo - senão o tráfico de negros" (p.136), aproximando-se da explicação de João Ribeiro.

A terra, gorda e farta, pedia apenas braços que a arroteavam, e falhando o elemento indígena, forçoso tornava-se recorrer àquele que tão belos resultados dera nas colônias africanas.

Abundante era o pasto: o gado humano, arrancado violentamente do solo nativo, bestificado pelos rigores da travessia, oprimido pelo azorraque do feitor, não podia reagir, não disporia da selva próxima e, passivamente, seria atrelado ao leito. E assim foi (REIS, 1915, p. 137).

Perdigão Malheiro, quando elabora seu ensaio sobre a escravidão em meados do século XIX, já denunciava essa justificativa sobre a escolha pela escravização dos negros:

Depois da descoberta da América (1492) começaram os negros a ser importados no Novo Mundo como poderosos instrumentos de trabalho; e assim como para o cativeiro dos índios diziam ser estes mais fortes que os europeus, assim para o dos negros alegavam ser melhores que os índios (MALHEIRO, 1964, p.15).

Malheiro (1964, p. 13) também critica a explicação dada pelos europeus, que trataram o tráfico como um resgate. "O 'resgate foi, pois, o título ou fundamento original para a escravidão dos negros, a quem se entendia prestar assim um imenso favor". Embora, segundo Malheiro, a cobiça tenha sido o real motivo deste comércio de negros transformados em mercadoria.

Nesse sentido, Borges do Reis, assim como Ribeiro e Rocha Pombo, reproduzem concepções sobre a escravidão há muito tempo divulgadas na sociedade brasileira. Concepções essas que estavam sendo levadas para a sala de aula.

Borges dos Reis prossegue na análise e apresenta alguns dados sobre o tráfico e seu desenvolvimento a partir da exploração mineral no Brasil. Não chega a citar fontes, mas traz números desse comércio.

A descoberta das minas, exigindo para sua exploração braços robustos, incrementa também muito a importação de escravos africanos, atingindo 15.000 a média anual dos que desembarcavam, presumindo-se acercar-se de 5 milhões a soma total de escravos que o Brasil recebeu.

O tráfico fazia-se claramente, legalmente, pelos povos mais adiantados da Europa, inclusive os inglezes, em cujas colônias a sorte do cativo era em extremo precária (REIS, 1915, p. 138).

Ele condena o tráfico e denuncia suas condições após a proibição desse comércio. Identifica, aí, toda a sorte de horrores e desumanidades que merece ser denunciada. Descreve com detalhes os horrores sofridos pelos negros africanos após lei de 1831 .

Mas os horrores do tráfico somente acentuaram-se e tomaram a feição infame e revoltante que espante a posteridade, quando de comércio legítimo, passou a ser contrabando.

[...] O risco desse comércio passou a ser maior desde que de livre tornouse perseguido, e a violência, a ausência de escrúpulos, a obliteração dos sentimentos de humanidade cresceram na razão direta dessa perseguição.

[...] $\mathrm{O}$ aspecto de um navio negreiro passou a ser horrível; e quando, na praia deserta do litoral brasileiro, conseguia o contrabandista despejar a carga, $30 \%$ dela ficava no porão apodrecida, e o aspecto da que desembarcava inspirava dó e lástima (REIS, 1915, p. 138). 
Além do tráfico, Borges dos Reis fala da lutas contra a escravidão. Não traz um capítulo específico sobre essa temática, mas, no capítulo XIII (Historia local, o norte Pernambuco), fala da experiência do quilombo dos Palmares como parte da história da capitania de Pernambuco. Relata a experiência do quilombo como uma perturbação da ordem colonial e justifica o uso da força para a sua destruição:

Um dos fatos culminantes de sua historia colonial foi a existência e a extinção do quilombo dos Palmares, singular Estado no estado, que durante 64 anos perturbou a vida econômica e social dessa parte da capitania, sendo necessário para extingui-lo congregar elementos requeridos para sua verdadeira campanha (REIS, 1915, p.164-165)5.

Por outro lado, ao relatar as características de Palmares, demonstra também conhecimento minucioso do funcionamento daquele quilombo e destaca a figura de Zumbi como corajosa e brava.

Quilombos dos Palmares foi a denominação que recebeu esse grande refugio de infelizes, urbes extensa de cerca de uma légua de circuito, defendida por uma dupla estaca de madeira, a guisa de praça forte, ensombrada por palmeiras, donde se lhes presume a denominação.

A organização social-religiosa do quilombo era um conjunto gentílico e cristão. O poder supremo cometiam vitaliciamente a um companheiro bravo e inteligente, condecorado com o título de príncipe ou Zumbi (REIS, 1915, p. 165-166).

Mesmo chamando a atenção para a força da bandeira paulista e do governo pernambucano, não deixa de destacar as atitudes heróicas dos negros liderados por Zumbi. Porém, ainda que reconhecesse esse heroísmo, fazia-se necessário, para Borges dos Reis, a destruição do quilombo.

Os negros, ao aproximar-se a expedição, haviam devastado as roças, recolhendo o seu produto a praça forte, onde se concentraram.

Lutando heroicamente, o Zumbi e seus principais companheiros, no momento extremo, suicidam-se, atirando-se de um despenhadeiro. Os sobreviventes do grande mocambo seguem cativos para o Recife. Distribuídos os quinhões do rei e dos expedicionários, é o resto vendido pelas outras capitanias (REIS, 1915, p.166).

No adentrar do território segue em parte o esquema de João Ribeiro (1900) na determinação dos vetores de formação do Brasil: o norte (Pernambuco), o centro (Bahia/Sergipe) e o sul (Rio de Janeiro). Mas Borges dos Reis fala aqui como baiano antes de ser brasileiro e lamenta a transferência do centro administrativo para o Rio de Janeiro por ter provocado a perda de prestígio da Bahia.

Os erros da metrópole contra a unidade administrativa, creando os governos independentes do Maranhão e do Rio Janeiro, foram enfraquecendo a importancia política da Bahia no regimen colonial, sendo afinal a séde do governo transferida para o Rio de Janeiro, 1763, providencia que as incorporações de Ilheus e de Porto Seguro, em 1579 e 1761, mal haviam compensado (REIS, 1915, p.178).

Era um intelectual baiano falando a partir dos ressentimentos de uma região outrora pujante e central no desenvolvimento da nação, que aquele momento encontrava-se em plena crise econômica.

Ainda em relação à ocupação do território, descreve as Bandeiras e Entradas existentes, destacando as figuras que lideraram as expedições.

Sua visão e representação da nação brasileira e seu nacionalismo fica patente quando descreve e analisa as invasões estrangeiras. Faz uma descrição do patriotismo dos 
luso-brasileiros, enaltecendo as reações de defesa do território pátrio, com destaque para o papel das três raças na luta contra os holandeses.

Nesse processo, destaca algumas figuras da chamada raças inferiores: o índio Poty (Felipe Camarão) e o negro Henrique Dias

Nesse assalto recebe o baptismo de fogo o valente preto Henrique Dias que, commandando uma companhia de homens de cor, havia se apresentado a Mathias de Albuquerque, trazendo a cooperação dos de sua raça à defesa do solo pátrio, permitindo assim não faltar ao prélio gigante, que então se feria, o concurso efficaz do terceiro factor ethnico da nossa nacionalidade (REIS, 1915, p. 93).

Condena a crueldade dos invasores ressaltando o fato de ter-se utilizado da "selvageria antropofágica" indígena contra os portugueses e os brasileiros, fato que cessou com a vinda de Nassau. A descrição da guerra contra os holandeses é permeada por exaltação do patriotismo dos luso-brasileiros, também aqui ele identifica a consolidação da defesa do território e da união das raças em nome de uma pátria única.

A retirada de Nassau succede a insurreição pernambucana - 1645-1654, último período de guerra hollandeza e, porcerto, o não menos brilhante, por manterem os luso-brasileiros em grau elevado a nota patriótica e altiva que sempre glorificou essa campanha (p. 107)

Assim termina a $2^{\mathrm{a}}$ invasão hollandeza, o mais notável episodio da historia colonial do Brazil, graças à tenacidade e ao heró́smo dos pernambucanos e portuguezes, a quem a Hollanda embaraçada pelas pertubações internas não pudera resisti (REIS, 1915, p. 114).

Prosseguindo na sua narrativa, informa muito brevemente sobre o processo de mineração, destacando sua importância para o progresso da colônia. No entanto, condena a cobiça exagerada que levou a conflitos como a guerra dos emboabas, na sua opinião sem espírito nativista, apenas interesses econômicos.

Outro marco fundamental na construção do sentimento patriótico foi a Inconfidência Mineira. Ressalta a influência das idéias de liberdade da Revolução Francesa e da Independência dos Estados Unidos da America, principalmente no desejo de instalação da República. Descreve os inconfidentes como intelectuais de prestígio, porém que não tinham um plano efetivo, logo o movimento foi "um sonho de poetas, sem plano regular, sem congregação de elementos, sem um chefe capaz de dirigir a revolução..." (p.207).

No tocante a Tiradentes, concorda que foi o mais otimista, embora inábil. Mesmo assim, reforça o seu heroísmo, cuja memória serve de lição de liberdade e ódio ao despotismo:

[...]Tiradentes encarna, a nosso ver, o que há de nobre e de bello nessa sublime aspiração de liberdade; já pelo seu ardor desinteressado, já pela coragem desprendida com que se arrojou á propaganda,já, finalmente, pela nobre e resignada atitude com que subiu ao patíbulo (REIS, 1915, p.208).

Este espírito patriótico foi responsável pela concretização da independência em 1822. Para Borges dos Reis esta foi gestada desde o século XVIII, acelerada com a vinda da família real em 1808. Reforça a importância deste acontecimento, ressaltando a necessidade da gradatividade e "pacifismo" do processo em nome da manutenção da nossa unidade política.

A abertura dos portos brazileiros ao commercio das nações amigas, como a fundação no seu territorio de fabricas e manufacturas, até então prohibidas, determinou de modo notavel a sua expansão economica e

Revista HISTEDBR On-line, Campinas, número especial, p. 145-163 mai.2010 - ISSN: 1676-2584 155 
financeira; a instalação no Rio de Janeiro das repartições publicas, centralisando no paiz a administração, unificando-a, foi um passo decissivo para sua emancipação politica.

De posse de taes beneficios, acostumado a taes regalias, seria impossivel ao apiz depois retargadas, voltar á condição de colonia e, por isso, o caracter de provisórios dado pelo Príncipe Regente aos actos que praticou, mudando-se para o Brazil e installando nelle o governo de seus domínios, foi uma ilusão de que participaram não só elle como, talvez, quantos collaboraram nessas resoluções [...] (REIS, 1915, p. 17).

Como parte do seu patriotismo baiano, detém-se na descrição dos conflitos e lutas entre portugueses e brasileiros na Bahia. Reforça a idéia do baiano patriota que lutou com toda guerra contra a resistência portuguesa e consolidou definitivamente nossa independência.

Outro momento de intensa demonstração de nacionalismo e patriotismo dos brasileiros foi durante a guerra contra o Paraguai.

Também concorda com a análise de Lopéz enquanto um ditador e provocador da guerra.

"Despercebido achava-se o Brazil para uma campanha tão monumentosa, quão formidável; não tinha esquadra suficiente, não possuia exercito regular e desguarnecidas encontravam-se suas extensas fronteiras.

Mas o patriotismo inflamma todos os peitos, e legiões de voluntários da pátria partem impávidas para as inhospidas regiões paraguayas, a vingar a honra nacional ultrajada" (REIS, 1915, p. 148)

Este patriotismo foi responsável, assim, pela vitória dos brasileiros na região platina e pela consolidação da soberania nacional.

Por fim Borges dos Reis chega à República. Ele busca nos movimentos coloniais de caráter nativista suas origens. Os ideais republicanos fazem parte, nessa concepção, dos primórdios do Brasil. A República é, aqui também, o destino esperado dos brasileiros. Sua realização foi a soma de vários acontecimentos como a criação do Partido Republicano, a abolição, os problemas militares e os erros politico-administrativos do Imperador.

Em relação à libertação dos escravos, Borges dos Reis apresenta como uma consequência da ação de parlamentares e abolicionistas, além de um desdobramento quase natural no desenrolar da história.

Reforça a importância do negro para o país, não apenas como escravo, mas posteriormente à abolição. "Elemento poderoso da prosperidade da colônia foi por certo o negro africano e os seos descendentes; elemento não menos valioso continuou a ser do nacional, quando o paiz alcansa a sua emancipação política” (REIS, 1915, 155).

Mesmo reconhecendo e valorizando o elemento negro na construção da nação, volta a trazer para o centro da História o homem branco que, na sua concepção, por bondade e filantropia, encaminha o processo da abolição.

Mas o espírito philantrópico dos brazileiros não se detém, era preciso extinguir a fonte da escravidão no paiz, e só bella conquista realiza-se com a lei de 28 de setembro de 1871, apresentado ao parlamento brazileiro pelo eminente estadista José Maria da Silva Paranhos, depois visconde do Rio Branco que, ao fazel-o triumphar empenhou as energias másculas do seo privilegiado talento (REIS, 1915, p. 156).

Por fim, informa brevemente que a lei foi sancionada pela Princesa Isabel, regente à época, sem, com isso, estabelecer qualquer papel de destaque ao fato. Nisso diferencia-se de outros manuais responsáveis pela construção do mito da redentora.

Revista HISTEDBR On-line, Campinas, número especial, p. 145-163 mai.2010 - ISSN: 1676-2584 156 
O manual de Borges dos Reis constrói dessa forma a trajetória do Brasil, marcada pelo patriotismo dos brasileiros, manifestadas em suas diversas regiões e pelas suas raças.

\section{Nação e identidade nacional - o debate continua....}

O livro didático foi aqui analisado a partir da compreensão de que ele representa uma importante leitura, às vezes fundadora, da idéia de nação brasileira. A obra e autor em análise representam expressões intelectuais de como o Brasil e a Bahia foram pensadas entre o final do século XIX e início do XX.

Além do jornalismo, o manual didático foi um caminho de produção trilhado por alguns desses intelectuais, que divulgavam seus projetos de nação por meio da narrativa da história do Brasil e da história da literatura brasileira. Mesmo considerando a inserção do Brasil no cenário capitalista internacional, de forma subordinada, os sujeitos sociais que viveram as incertezas e esperanças dos seus contextos buscavam, na medida dos seus interesses de classe, construir um futuro, transformar o Brasil em uma "nação civilizada". Nação aqui entendida sob o aspecto de uma "tradição inventada" num determinado tempo e espaço, como bem nos mostram Hobsbawm e Ranger quando conceitua tradição inventada.

[...] um conjunto de práticas, normalmente reguladas por regras tácita ou abertamente aceitas; tais práticas, de natureza ritual ou simbólica, visam inculcar certos valores e normas de comportamento através da repetição, o que implica, automaticamente, uma continuidade em relação ao passado. Aliás, sempre que possível, tenta-se estabelecer continuidade com um passado histórico apropriado. (HOBSBAWM e RANGER, 2002, p. 9).

É nessa perspectiva que o conceito de nação e nacionalismo é utilizado na análise aqui proposta. Esse tipo de nacionalismo, do final do século XIX, para Hobsbawm (1990), se diferencia do patriotismo estatal anterior, pois "sua lealdade básica não era, paradoxalmente, ao 'país', mas à sua versão particular de país: com um construto ideológico" (p. 113).

Portanto, o livro didático relativo à história do país e à língua nacional foi fundamental para consolidação de uma nacionalidade comum a todos. O autor didático investigado aqui pode, nesse sentido, ser classificado como construtor de determinada visão de nação e nacionalidade dominante no Brasil nos finais do século XIX. No entanto, essa nacionalidade adquiriu especificidades e características relacionadas ao lugar de onde se falava.

O livro didático de história do Brasil considerado na sua condição de um veículo fundamental na divulgação e consolidação de um projeto de classe hegemônico, se caracterizou, nesse período, pela defesa de uma sociedade urbana, liberal, capitalista, branca e cristã. A escola secundária, como instituição oficial e formadora, naquele momento, das classes dominantes, foi o espaço privilegiado para que este projeto fosse divulgado e socializado na sociedade.

O livro didático de história do Brasil, dessa forma, nos diz muito do seu contexto de produção e das concepções dos seus autores e da sociedade. Analisá-lo sob o ponto de vista da história da educação enriquece, na nossa opinião, o debate em torno dos significados e papéis assumidos pela escola ao longo do tempo.

O manual didático aqui analisado investiu na explicação da história por via dos focos de expansão do território, trazendo para discussão o interior e seus habitantes e declarando uma influência explícita do modelo historicista alemão segundo Von Martius, como, também, imaginamos nós, de historiadores brasileiros preocupados naquele 
momento com as questões do sertão, Capistrano de Abreu e Euclides da Cunha particularmente.

Seu autor - Borges dos Reis - teve a experiência de lecionar história do Brasil numa instituição escolar e construiu o livro para tal fim. Ele viveu intensamente as transformações sociopolíticas, econômicas e culturais da transição do século XIX para o século XX, participando ativamente da vida intelectual baiana. Era ligado ao Instituto Geográfico e Histórico da Bahia. Assim, sua obra foi marcada pelos princípios do Instituto Histórico e Geográfico Brasileiro (IHGB), fundado em 1839 com o objetivo de "colligir, methodizar e guardar documentos, fatos e nomes, para finalmente compor uma história nacional para este vasto país carente de delimitações não só territoriais" (SCHWARCZ, 1993, p.99).

O IHGB foi hegemonizado, n/as suas primeiras décadas, pelas elites agrárias regionais, cujo interesse era construir e preservar a memória de sua classe associada à da nação. Schwarcz (1993) discute como esse Instituto foi responsável pela construção da história da nação, marcada por um saber de cunho oficial e de "exaltação e glória da pátria", utilizando símbolos, monumentos, medalhas e hinos.

A produção do conhecimento histórico pelo IHGB também foi marcada pelo debate em torno da questão racial na formação do Brasil6. O negro era visto à luz de uma visão determinista e fatalista quanto à sua impossibilidade de integração na sociedade. No final do século XIX, numa sociedade pós-abolição, o negro foi analisado sob a perspectiva eugênica7.

Borges dos Reis, assim como outros autores didáticos de sua época, construiu seu manual com a intenção de estabelecer e divulgar determinada visão do Brasil e projetar um futuro para o país. Deu uma explicação para a formação do brasileiro, cuja caracterização sócio-racial foi fundamental no pensar sobre a sua identidade como povo. Para tanto, as análises sobre o negro na condição de escravo e sobre a abolição foram essenciais ao entendimento do lugar ocupado por esse grupo étnico na identidade nacional.

No geral, sua obra sustenta-se numa visão de história como manifestação da trajetória da formação da nação brasileira, consolidada com a Proclamação da República, cujo percurso firmou uma determinada identidade nacional. Lembramos as influências sofridas pelos historiadores do século XIX de autores como Guizot, que produziu uma obra grandiosa sobre o nascimento das nações. Fontana (2004) analisa essa influência, destacando, principalmente, o fato de Guizot trazer para o centro da narrativa a trajetória das nações a partir da burguesia em ascensão, colocando em evidência a "sociedade civil" e não mais reis e dinastias, constituindo-se, assim, na concepção de Fontana, um dos fundadores da história das nações.

Em Borges dos Reis essa concepção transparece de forma contundente. As classes dominantes, não necessariamente dinásticas, assumem a posição de fundadores da nação, representadas pelos jesuítas e colonizadores.

Como parte dessa concepção de história, o escravo negro aparece como elemento formador, e não fundante, da nação brasileira. Fortalece a presença das raças e suas relações na construção do componente racial brasileiro. Destaca, muitas vezes, em tom de denúncia, a crueldade da escravidão, porém a justifica em nome de um projeto maior - a construção da nação brasileira livre e soberana. Ele explica a escravidão como uma peculiaridade do próprio negro. No entanto, a análise sobre o papel dos escravos e sua inserção na formação do Brasil é marcante na explicação da trajetória nacional. O negro escravo é um elemento que merece explicação tanto do ponto de vista do seu papel produtivo, quanto do ponto de vista das influências raciais. 
Essa era uma visão dominante no ensino de história do Brasil naquele momento. Nadai reconstrói a trajetória desse ensino identificando tanto a influência do IHGB como das produções francesas, que construíram uma disciplina escolar marcada pela história da civilização e da nação, formada pela colaboração das três raças. Esses elementos eram, por sua vez, fortemente influenciados pelas explicações da antropologia. O currículo de história das escolas secundárias, no início do período republicano, tinha a preocupação de expressar as idéias de nação e de cidadão embasadas na identidade comum dos seus variados grupos étnicos e classes sociais constitutivos da nacionalidade brasileira (Nadai, 1993).

No entanto, o autor didático aqui analisado não fica preso a hierarquias raciais estáticas. Quando analisa o processo de resistência à escravidão demonstra certa simpatia pelos negros e por sua coragem, condena a escravidão, ainda que permaneça imbuído da visão de inferioridade da raça negra e da sua função nesta pátria. De uma maneira geral, demonstra simpatia pela causa abolicionista e percebe sua necessidade.

Pode-se afirmar que Borges dos Reis estava envolvido com as idéias liberais, defensores de uma ordem capitalista industrial que despontava para o "novo mundo", porém casava muito bem seus ideais com a legitimidade da escravidão. Bosi, ao comentar o livro de Losurdo sobre Liberalismo e escravidão, nos dá uma idéia desse casamento:

A relação entre doutrina liberal e escravidão, que, teoricamente, pareceria uma disjuntiva radical, revela-se na "verità effettuale della cosa" (não por acaso, expressão de Maquiavel) uma conjunção reiterável nos mais diversos contextos. Começando por John Locke: solicitado pelos proprietários da Carolina a colaborar na redação das Constituições daquela colônia, o filósofo subscreveu um artigo (de n.110) pelo qual "todo homem livre da Carolina deve ter absoluto poder e autoridade sobre seus escravos negros, seja qual for sua opinião e religião". (BOSI, 2007)

Esta concepção liberal pode ser percebida na visão da história do Brasil construída pelo autor didático aqui em foco. Em seu manual defendeu uma nação que se sustentava num determinado modelo de trabalho e de relações sociais de classe. Representante do seu tempo e de sua classe, esse autor fundamentou suas análises numa concepção de sociedade que nos ajuda a identificar como esses materiais didáticos foram essenciais na conformação de uma ideologia que implicava a manutenção de uma determinada ordem social.

Além disso, ele falava como autor institucional, seu manual foi legitimado por uma instituição escolar oficial, referendada socialmente. O Ginásio da Bahia, seguindo o modelo do Colégio Pedro II, constituía naquela época um espaço de reprodução e divulgação de um projeto de sociedade hegemônico. A Bahia republicana viveu o processo do pós-abolição inserida numa crise econômica de perda de hegemonia para o sudeste, porém, mantendo hierarquias sociais sustentadas em prestígio político, fortemente marcado pela cor/raça. A sociedade baiana, particularmente a cidade da Bahia, enfrentou a contradição da presença maciça da população negra recém-saída da escravidão e os percalços na organização de um modelo de sociedade urbana, branca e européia.

Essa questão estava presente na instituição escolar, principalmente no Ginásio da Bahia, que representou um importante centro de formação da elite baiana, que aglutinava intelectuais ligados às classes dominantes responsáveis pela formação de opinião e participantes ativos em outros espaços de circulação de idéias como os jornais e o Instituto Geográfico e Histórico da Bahia (IGHB).

Durante quase todo o período colonial, o ensino no Brasil foi responsabilidade dos padres jesuítas e não se constituía num sistema mais geral para a maioria da população. 
Adentrando o Império, já com grande parte dos jesuítas longe do Brasil, iniciou-se o processo de organização de um sistema oficial de ensino8. Com a Lei de Ensino, de 1827, o governo brasileiro se comprometeu a construir escolas de primeiras letras para meninos e meninas em toda vila brasileira.

Em finais do século XIX e no adentrar da República, essas concepções ganham novas formas, acentuam-se as críticas a uma história sagrada e se inicia a constituição de uma identidade nacional sustentada no nacionalismo patriótico, cujo passado nacional precisava ser escrito de forma homogênea, sem conflitos e único para todos os brasileiros (BITTENCOURT, 2007).

Esse patriotismo assume perspectivas diferenciadas a partir das particularidades regionais. Investigar essas particularidades na obra de Borges dos Reis é importante por tratar-se de um autor que representava um grupo social específico e, em muitos momentos, falava a partir de instituições centrais na formação da visão de mundo de gerações de baianos.

Com o desdobramento dessas primeiras reflexões, espera-se melhor compreender um período da história da Bahia marcado por intensos debates em torno da situação econômica e política frente ao cenário mundial e nacional. Além disso, os intelectuais baianos do início do século passado circulavam em espaços institucionais diversos Faculdade de Medicina, Ginásio da Bahia, IGHB, ABL, jornais - possibilitando uma maior divulgação e circulação das duas idéias e uma repercussão dessas nas políticas implementadas. Logo, seu estudo possibilita uma compreensão das ações e escolhas políticas ocorridas na Bahia neste período.

Dessa forma, com a análise do livro didático de Borges dos Reis foi possível entender em parte a questão específica da conformação de uma identidade nacional, relacionada com as configurações da sociedade baiana, brasileira e mundial dos finais do dezenove e primeiras décadas do século vinte.

Assim, entender intelectual, livro didático e nação brasileira sob a ótica da produção baiana possibilita ampliar o olhar sobre as diversas representações e construção da idéia de nação brasileira, além de evidenciar os interesses e estratégias de classe internas a essas representações.

\section{REFERÊNCIAS}

ABREU, Capistrano de (1988). Caminhos antigos e povoamento do Brasil, Belo Horizonte: Itatiaia, São Paulo: Edusp.

ARAÚJO, D. O. de (1993). Republicanismo e classe média em Salvador, 1870-1989. Dissertação (Mestrado em Ciências Sociais), Salvador: FFCH, UFBA.

ARAÚJO, U. C. de (2000). A baía de Todos os Santos: um sistema geo-histórico resistente. Bahia Análise e Dados, v.1. Salvador: Superintendência de Estudos Econômicos e Sociais da Bahia.

BITTENCOURT, C. (2007). Identidade e ensino de história no Brasil. IN: CARRETERO, M.; ROSA, Alberto e GONZÁLEZ, M. F. (orgs) Ensino de História e memória coletiva. Porto Alegre, Artmed.

Revista HISTEDBR On-line, Campinas, número especial, p. 145-163 mai.2010 - ISSN: 1676-2584 160 
(1993). Livro didático e conhecimento histórico: uma história do saber escolar. Tese (Doutorado em História) São Paulo: USP/FFLCH.

BLOCH, Marc (1997). Introdução à História. Lisboa: Publicações Europa-América. COSTA, E. V. da (1999). Da Monarquia à República: momentos decisivos. São Paulo, Brasiliense.

COSTA, I. S. (1997). A Bahia já deu régua e compasso: o saber médico-legal e a questão da racial na Bahia, 1890-1940. Salvador, 1997. Dissertação (Mestrado em História) — FFCH, UFBA.

CUNHA, E. (1975). Os Sertões. São Paulo: Cultrix.

FERREIRA FILHO, A. H. (1999) Desafricanizar as ruas: elites letradas, mulheres pobres e cultura popular em Salvador (1890-1937). Revista Afro-Ásia, n. 21-22, Salvador, Centro de Estudos Afro-Orientais, FFCH-UFBA.

FONSECA, T. N. L. e VEIGA, C. G. (orgs). (2003). História e Historiografia da Educação no Brasil. Belo Horizonte: Autêntica.

FONSECA, T. N. de L. (2004). História \& Ensino de História. $2^{a}$ edição. Belo Horizonte: Autêntica.

FONTANA, J. (2004). A História dos Homens. Bauru: EDUSC.

GUIMARÃES, A. S. (2003). Formação e crise da hegemonia burguesa na Bahia. Dissertação (Mestrado em Ciências Sociais) Salvador, UFBA - revista pelo autor em 2003. HALLEWELL, L. (2005). O livro no Brasil: sua história. 2. ed. rev. e .ampl. São Paulo: Edusp.

HOBSBAWN, E. (1990). Nações e nacionalismo desde 1780: programa, mito e realidade. Rio de Janeiro: Paz e Terra.

HOBSBAWN, E.; RANGER, T. (2002). A invenção das tradições. $3^{a}$ edição.São Paulo: Paz e Terra.

HOBSBAWN, E. (1992). A Era dos Impérios: 1875-1914. 3 ed. Rio de Janeiro: Paz e Terra, 1992.

LEITE, R. C. N. (2005). A Rainha Destronada: Discursos das Elites sobre as Grandezas e os Infortúnios da Bahia nas Primeiras Décadas Republicanas. São Paulo: PUC/SP, Doutorado em História Social.

LIMA, D. K. O Banquete Espiritual da Instrução: o Ginásio da Bahia, Salvador: 1895-1942. Salvador, Universidade Federal da Bahia, 2003, (Dissertação de Mestrado em História Social).

LOMBARDI, J. C.; CASIMIRO, A. P. e MAGALHÃES, L. D. (orgs). (2006). História, Cultura e Educação. Campinas, SP: Autores Associados.

MACHADO NETO, A. L. (1972). A Bahia intelectual. Universitas - Revista de Cultura da UFBA, Salvador, n. 12/13, p. 261-305.

MARX, K. (1997). O 18 Brumário e Cartas a Kugelmann. Rio de Janeiro: Paz e Terra.

MATTOSO, K. de Q. (1992). Bahia século XIX. Uma Província no Império, Rio de Janeiro: Nova Fronteira.

MELLO, C. F. de C. B. de. (1997) Senhores da História: a construção do Brasil em dois manuais didáticos de história na segunda metade do século XIX. São Paulo: USP/FFLCH (Tese de Doutorado).

NADAI, E. "O ensino de história e a pedagogia do cidadão". In: PINSKY, Jaime (org). O ensino de história e a criação do fato. São Paulo: Contexto, 1997.

NAGLE, J. Educação e sociedade na Primeira República. Reimpressão. São Paulo; EPU, 1976. 
NUneS, A. A. Política Educacional no início da Primeira República na Bahia: duas versões do projeto liberal. Salvador: Faced/UFBA, 2003 (Tese de doutorado).

OLIVEIRA, F. de (2003). O Elo Perdido: classe e identidade de classe na Bahia. São Paulo, Editora Perseu Abramo.

ORTIZ, R. (2003). Cultura Brasileira e Identidade Nacional. São Paulo: Brasiliense.

PINA, M. C. D. (2009). A escravidão no livro didático de História: três autores exemplares (1890-1930). Doutorado em Educação. Faculdade de educação, Unicamp. (Tese de Doutorado).

REIS FILHO, Casimiro dos (1995). A educação e a ilusão liberal. São Paulo: Cortez, Autores Associados.

REIS, M. L. A. dos (2000). A cor da notícia: discursos sobre o negro na imprensa baiana (1888-1937). Salvador, Dissertação (Mestrado em História) - FFCH, UFBA.

REZNIK, L. (1992). Tecendo o amanhã: a História do Brasil no ensino secundário: programas e livros didáticos, 1931 a 1945. Niterói, RJ: IFCS/UFF (Dissertação de Mestrado em História).

SAMPAIO, C. N. (1985). O poder legislativo na Bahia: Primeira República (1889-1930). Salvador, Assembléia Legislativa/UFBA, 1985.

SANTOS, F. G. dos. (2001). Os discursos afro-brasileiros face às ideologias raciais na Bahia (1889-1937). Salvador, 2001. Dissertação (Mestrado em História) - FFCH, UFBA. SAVIANI, D. (2007). História das Idéias Pedagógicas no Brasil. Campinas, SP: Autores Associados.

SILVA, A. J. M. (2006). Instituo Geográfico e Histórico da Bahia: origem e estratégias de Consolidação Institucional 1894 - 1930. Salvador: Universidade Federal da Bahia (Tese de Doutorado em História)

SILVA, P. S. (2000). Âncoras de Tradição: luta política, intelectuais e construção do discurso histórico na Bahia (1930 - 1949). Salvador: EDUFBA.

TAVARES, L. H. (2001). História da Bahia. São Paulo: Editora UNESP: Salvador: EDUFBA.

THOMPSON, E. P. (1981). A Miséria da Teoria. Rio de Janeiro: Zahar Editores.

VIDAL e SOUZA, C. (1997). A Pátria Geográfica: sertão e litoral no pensamento social brasileiro, Goiânia: UFG.

XAVIER, M. E. S. P. Capitalismo e Escola no Brasil. Campinas, SP: Papirus, 1990.

Livros Didáticos

BORGES DOS REIS, Antonio Alexandre (1915). História do Brasil (cursos dos Gymnásios e Lyceus). Bahia: Typografia Reis \& Cia.

RIBEIRO, João. (1900). História do Brasil. Rio de Janeiro: Livraria Cruz Coutinho.

ROCHA POMBO, J. F. da. (1958) História do Brasil, $8^{\text {a }}$ ed. revista e atualizada por Helio Vianna. São Paulo, Companhia Melhoramentos de São Paulo.

Notas:

\footnotetext{
${ }^{1}$ Este texto constitui uma versão modificada de parte do terceiro capítulo da minha tese de doutorado PINA, M. C. D. (2009). A escravidão no livro didático de História: três autores exemplares (1890-1930). Doutorado em Educação. Faculdade de educação, Unicamp..

${ }^{2}$ As informações sobre o autor aqui relatadas foram retiradas de CASTRO, Renato Berbet de. Os fundadores da Academia de Letras da Bahia. Salvador: Secretaria de Cultura e Turismo, EGBA, 1998.
}

Revista HISTEDBR On-line, Campinas, número especial, p. 145-163 mai.2010 - ISSN: 1676-2584 162 
${ }^{3}$ Refere-se aqui a pesquisa desenvolvida por nós no doutorado na qual se analisou os manuais didáticos de João Ribeiro, Rocha Pombo e Borges dos Reis no que diz respeito a questão da escravidão (PINA, 2009).

4 Borges dos Reis produziu um estudo específico sobre os indígenas baianos - "Os indígenas da Bahia" -, publicado pelo autor em 1920. Antes tinha sido lido no dia 3 de maio de 1900 no IGHB, em seção de comemoração ao $4^{\circ}$ centenário da descoberta do Brasil.

${ }^{5}$ Grifo nosso.

${ }^{6}$ É exemplar desse debate o concurso promovido pelo Instituto sobre como deveria ser escrita a história do Brasil, e do qual foi vencedor Von Martius, com a monografia sobre a influência e o papel das três raças nessa história, o que terá exercido grande influência na produção didática de João Ribeiro, como citado anteriormente.

${ }^{7}$ São exemplares as análises de: Nina Rodrigues, 1933, 1935; Euclides da Cunha, 1902; e Silvio Romero, 1888. Destaca-se, como visão diferenciada em relação a essa temática, Manoel Bonfim, que apresenta a história da América Latina a partir da denúncia da exploração efetuada pelos países desenvolvidos desde a colonização.

${ }^{8}$ A discussão sobre a necessidade de um sistema nacional de ensino inicia-se nesse momento, embora, na prática, ele só se efetivará a partir dos anos 1930. Ver sobre esta discussão SAVIANI, 2007

Artigo recebido em: 09/04/2010

Aprovado para publicação em: 02/06/2010 